\title{
Synthesis and thermochemical redox cycling of porous ceria microspheres for renewable fuels production from solar-aided water-splitting and $\mathrm{CO}_{2}$ utilization
}

\author{
Stéphane ABANADES ${ }^{1 *}$, Anita HAEUSSLER ${ }^{1}$, Anne JULBE $^{2}$ \\ ${ }^{1}$ Processes, Materials and Solar Energy Laboratory, CNRS-PROMES, 7 Rue du Four Solaire, \\ 66120 Font-Romeu, France \\ ${ }^{2}$ Institut Européen des Membranes, IEM, UMR-5635, ENSCM, CNRS, Univ Montpellier, \\ Place Eugène Bataillon, 34095 Montpellier cedex 5, France \\ * Corresponding author: Tel +33 (0)4 68307730 \\ E-mail address: stephane.abanades@promes.cnrs.fr
}

\begin{abstract}
:
Porous ceria-based architected materials offer high potential for solar fuels production via thermochemical $\mathrm{H}_{2} \mathrm{O}$ and $\mathrm{CO}_{2}$-splitting cycles. Novel porous morphologies and micro-scale architectures of redox materials are desired to provide suitable thermochemical activities and long-term stability. Considering particle-based solar reactors, porous ceria microspheres are promising because of their excellent flowability and large surface area. In this work, such porous microspheres with perfect spherical shape, high density and interconnected pore network were fabricated by a chemical route involving ion-exchange resins. The method involved the cationic loading of the resin in aqueous medium followed by thermal treatment for oxide formation and porous microstructure stabilization. The utilization of these microspheres ( 150-350 $\mu \mathrm{m}$ in size) as redox materials for solar fuel production was investigated in packed-bed solar reactors (directly and indirectly-irradiated). Superior redox performance was obtained for the pure ceria microspheres in comparison with other morphologies (powders and reticulated foams). Low $p_{\mathrm{O} 2}$ values thermodynamically favored the reduction extent and associated fuel yield, whereas high $p_{\mathrm{CO} 2}$ kinetically promoted the oxidation rate. The highest fuel production rate reached $1.8 \mathrm{~mL} / \mathrm{min} / \mathrm{g}$ with reduction step at $1400^{\circ} \mathrm{C}$ and low total pressure $\left(\sim 0.1\right.$ bar), and oxidation step below $1050^{\circ} \mathrm{C}$ under pure $\mathrm{CO}_{2}$. Low pressure during reduction both improved reduction extent (oxygen under-stoichiometry $\delta$ up to 0.052$)$ and associated fuel production yield $(331 \mu \mathrm{mol} / \mathrm{g} \mathrm{CO})$. After 19 redox cycles ( $\sim 32 \mathrm{~h}$ under high-flux solar irradiation), the porous microspheres maintained their individual integrity (no agglomeration), spherical shape, and internal porosity, with great potential for stable fuel production capacity in particle-based solar reactors.
\end{abstract}

Keywords: thermochemical cycles, ceria, hydrogen production, $\mathrm{CO}_{2}$ valorization, solar reactor, porous microspheres 
Solar fuels production via thermochemical splitting of water and carbon dioxide using twostep redox cycles represents an attractive and sustainable pathway for solar energy conversion and storage into dispatchable energy carriers. Concentrated solar energy is used to provide the required thermal energy for the thermochemical reactions ${ }^{1-4}$. This efficient route for $\mathrm{H}_{2}$ synthesis and/or $\mathrm{CO}_{2}$ conversion potentially outperforms the electrolytic and photochemical routes, because thermochemical processes utilize the entire solar spectrum and directly convert high temperature heat to clean and carbon-neutral chemical fuels. The intermediate production of electricity (via photovoltaics or concentrated solar power) or the use of photocatalysts is thus not required. Ceria is an attractive material for two-step redox cycling, due to high oxygen mobility, ability for creation of lattice oxygen vacancies, rapid reaction kinetics with reversible $\mathrm{Ce}^{4+} / \mathrm{Ce}^{3+}$ transition, stable crystal structure and resistance to sintering during cycling ${ }^{5,6}$. Ceria $\left(\mathrm{CeO}_{2}\right)$ is first partially reduced to a non-stoichiometric state $\left(\mathrm{CeO}_{2-\delta}\right)$ with oxygen release using concentrated solar thermal energy. During a second oxidation step, $\mathrm{H}_{2}$ fuel is produced from $\mathrm{H}_{2} \mathrm{O}$ dissociation, while $\mathrm{CO}_{2}$ is converted to $\mathrm{CO}^{7-15}$. When combined with $\mathrm{H}_{2}$, the syngas $\left(\mathrm{H}_{2} / \mathrm{CO}\right.$ mixture $)$ can be further processed to methane and liquid hydrocarbon fuels via methanation and Fischer-Tropsch processes. Beyond the intrinsic redox activity of ceria, an appropriate material shaping is required for efficient and stable redox cycling performance and integration in solar reactors. Indeed, porous materials with interconnected open porosity are required to guarantee i) efficient access of the gaseous species to the bulk material, ii) enhanced heat and mass transfer, and iii) high available specific surface area for gas-solid reactions. The utilization of powders in solar reactors is usually not appropriate because of densification/agglomeration/sintering issues and loss in activity during cycling. The most relevant morphologies that were previously investigated for two-step cycles include reticulated porous ceramics $(\mathrm{RPC})^{16-20}$, fibers/felts ${ }^{21-23}$, threedimensionally ordered macroporous (3DOM) structures $^{24-26}$, and biomimetic materials prepared from bio-templates ${ }^{27-30}$. The structured materials must have low optical thickness (low opacity) for efficient volumetric radiation absorption (enabling limited thermal gradients), while being sufficiently dense for high ceria mass loading in the reactor with a thermally-stable macroporous network for gas-solid reactions.

In this work, solar-driven thermochemical $\mathrm{H}_{2} \mathrm{O}$ and $\mathrm{CO}_{2}$-splitting cycles using ceria porous microspheres were investigated in packed-bed solar reactors, providing an efficient route to convert intermittent and dilute solar energy into high-value chemical fuels. Such a spherical porous morphology was never investigated before for concentrating solar applications. The 
microspheres exhibit several key advantages including: (i) perfect spherical shape inducing high flowability and stacking ability, enabling optimal reactor volume filling and redox material loading, (ii) high interconnected porosity favoring gas species transfer with low pressure drop and access of the oxidant gas to the reactive surface (enhancing kinetics), (iii) tunable specific surface area and pore density, (iv) chemical composition versatility.

The considered ceria microstructured spheres (abbreviated as CeMS) were synthesized by a process involving ion-exchange resins $^{31,32}$. A polyacrylic resin constituted of porous microspheres was washed successively with an aqueous nitric acid solution, an aqueous ammonia solution and then deionized water. This protocol was used both to remove all the exchangeable cations and chemical impurities from the resin and to convert it to its ammonium form. Then, the resin was loaded with cerium by immersion in an aqueous solution of $\mathrm{Ce}^{3+}$ ions, obtained by dissolution of cerium nitrate in pure water. The ionized or ionizable groups of the polyacrylic resin (carboxylate groups compensated by $\mathrm{NH}_{4}{ }^{+}$cations) offer strong affinity for the $\mathrm{Ce}^{3+}$ ions. This guarantees a quantitative fixation of $\mathrm{Ce}^{3+}$ ions at atomic scale with good homogeneity. After the cation exchange, the resin was first rinsed with pure water to remove the excess of non-fixed cations. Then, it was dried for $12 \mathrm{~h}$ at $100{ }^{\circ} \mathrm{C}$ to remove the water contained in the resin. Afterward, a first ceramization thermal treatment in air $\left(4 \mathrm{~h}\right.$ at $800^{\circ} \mathrm{C}$, heating ramp of $1^{\circ} \mathrm{C} / \mathrm{min}$, free cooling) was used to remove the organic skeleton from the material. A second thermal treatment $\left(4 \mathrm{~h}\right.$ at $1400^{\circ} \mathrm{C}$, heating ramp of $5^{\circ} \mathrm{C} / \mathrm{min}$ up to $800^{\circ} \mathrm{C}$ and $1{ }^{\circ} \mathrm{C} / \mathrm{min}$ up to $1400^{\circ} \mathrm{C}$, free cooling) was used to stabilize the ceria microstructure and its morphology for high temperature applications. The final ceria particles were porous spheres (diameter in the range 150-350 $\mu \mathrm{m}$ ) with mainly open intraparticle porosity ( $\sim 36 \%$ of the microsphere volume; pore sizes in the range $0.5-2 \mu \mathrm{m})$. The specific surface area measured by BET method was $0.3 \mathrm{~m}^{2} / \mathrm{g}$. Moreover, the randomclose microspheres packing provided interparticle porosity $(\sim 36 \%$ of the microsphere bed; pore sizes of one third of the microsphere diameter, i.e. $\sim 100 \mu \mathrm{m})$. Such open and interconnected porosities favor an easy penetration/diffusion of gas species inside the bed and particles.

The porous microspheres were first investigated via thermogravimetric analysis (TGA) to characterize their redox activity in comparison with ceria-based powders (including $\mathrm{CeO}_{2}$, $\mathrm{Ce}_{0.8} \mathrm{Gd}_{0.2} \mathrm{O}_{2}$, and $\mathrm{Ce}_{0.9} \mathrm{Zr}_{0.1} \mathrm{O}_{2}$ prepared via Pechini method ${ }^{33}$ ) (Fig. 1). The reduction was performed in $\mathrm{Ar}$ at $1400^{\circ} \mathrm{C}$ (during $45 \mathrm{~min}$ ) and the oxidation in $\mathrm{Ar} / \mathrm{CO}_{2}\left(50 \% \mathrm{CO}_{2}\right)$ at 
$1050^{\circ} \mathrm{C}$ (60 min). Thanks to its favorable microstructure, CeMS showed higher fuel production rates $(\sim 1.2 \mathrm{~mL} / \mathrm{min} / \mathrm{g})$ compared to powders (Table 1). The addition of $\mathrm{Zr}^{4+}$ enhanced the reduction extent, but the oxidation rate was lowered and the oxidation extent was not complete $\left(\mathrm{n}_{\mathrm{CO}}<2 . \mathrm{n}_{\mathrm{O} 2}\right)$. The addition of $\mathrm{Gd}^{3+}$ decreased the amount of $\mathrm{O}_{2}$ being released (because the amount of reducible $\mathrm{Ce}^{4+}$ cations was decreased), thus in turn decreasing the total $\mathrm{CO}$ yield (the oxidation kinetics was however very fast). The best performing material regarding its stability, fuel yield and oxidation kinetics was thus pure ceria. CeMS produced $\sim 99 \mu \mathrm{mol} / \mathrm{g} \mathrm{CO}$ (twice the $\mathrm{O}_{2}$ amount). This value is similar to the fuel yield produced by micron-sized ceria powder $(\sim 100 \mu \mathrm{mol} / \mathrm{g} \mathrm{CO})^{33-36}$, thereby indicating that the use of porous ceria microspheres allows maintaining the material reactivity without any loss of performance. Powder bed densification is moreover bypassed since the stacking of microspheres remains unchanged and is not altered during cycling. The stable morphology and microstructure of the microspheres guarantee efficient mass transfer (access of gaseous species to the material bulk) and stable thermochemical performance.

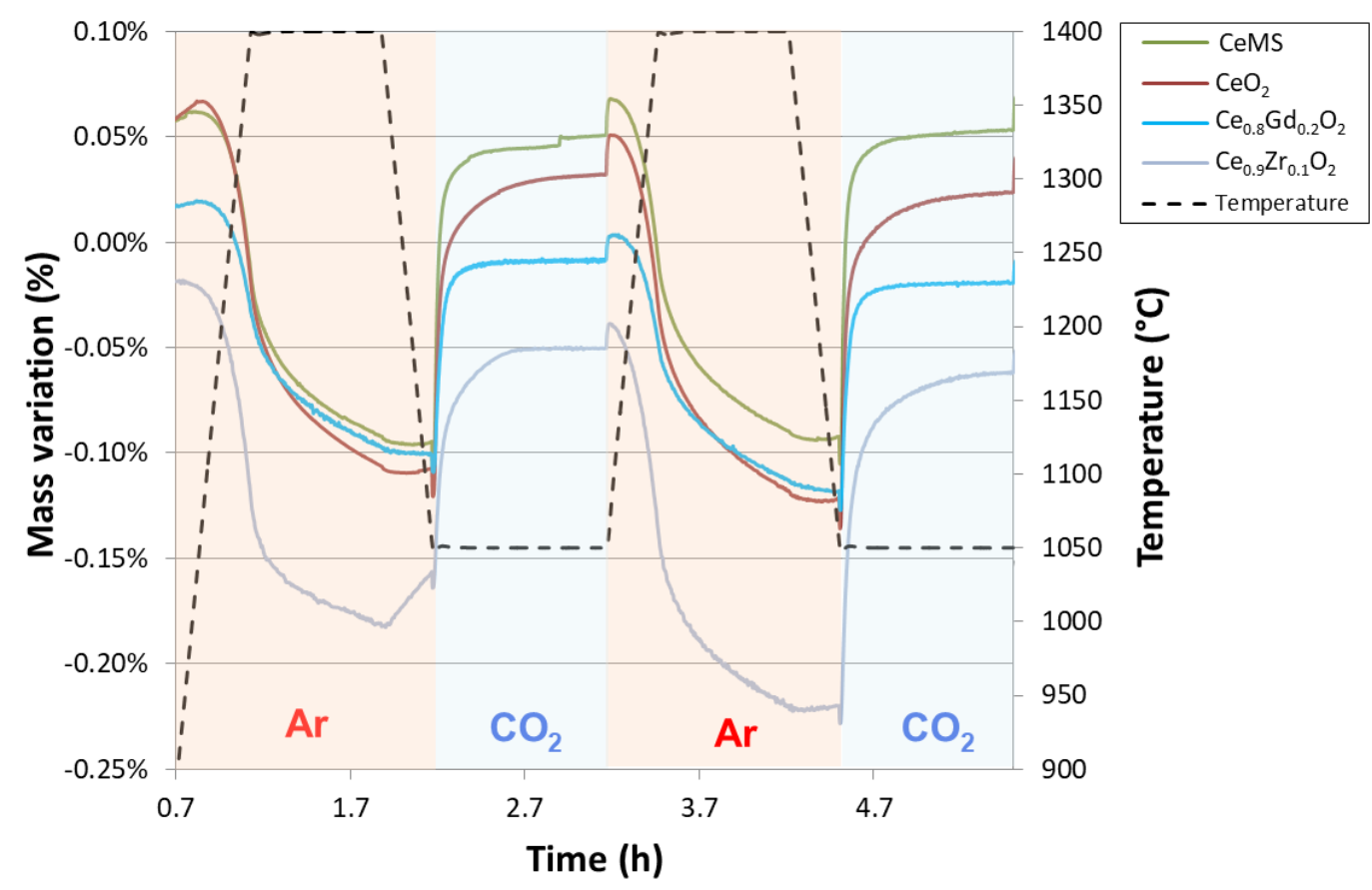

Figure 1: Reduction and re-oxidation profiles of CeMS and ceria-based powders during temperature-programmed TGA. 
Table 1: $\mathrm{O}_{2}$ and $\mathrm{CO}$ produced from CeMS and from ceria-based powders in TGA, along with the non-stoichiometry extents $(\delta)$, re-oxidation yields and peak production rates.

\begin{tabular}{|c|c|c|c|c|c|c|}
\hline \multirow[b]{2}{*}{ Cycle \# } & \multicolumn{3}{|c|}{ Reduction step } & \multicolumn{3}{|c|}{ Oxidation step } \\
\hline & $\begin{array}{c}\mathrm{O}_{2} \\
\text { produced } \\
(\mu \mathrm{mol} / \mathrm{g})\end{array}$ & $\begin{array}{c}\boldsymbol{\delta} \\
\mathrm{mol} / \mathrm{mol}\end{array}$ & $\begin{array}{c}\text { Peak } \mathrm{O}_{2} \\
\text { production } \\
\text { rate } \\
(\mathrm{mL} / \mathrm{min} / \mathrm{g} \\
)\end{array}$ & $\begin{array}{c}\text { CO } \\
\text { produced } \\
(\mu \mathrm{mol} / \mathrm{g})\end{array}$ & $\begin{array}{c}\text { Re- } \\
\text { oxidation } \\
\text { yield }\end{array}$ & $\begin{array}{c}\text { Peak CO } \\
\text { production } \\
\text { rate } \\
(\mathrm{mL} / \mathrm{min} / \mathrm{g} \\
)\end{array}$ \\
\hline \multicolumn{7}{|c|}{$\mathrm{Ce}_{0.9} \mathrm{Zr}_{0.1} \mathrm{O}_{2}$ powder } \\
\hline 1 & 51 & 0.017 & 0.096 & 82 & $80 \%$ & 0.456 \\
\hline 2 & 57 & 0.019 & 0.096 & 103 & $90 \%$ & 0.623 \\
\hline \multicolumn{7}{|c|}{$\mathrm{Ce}_{0.8} G d_{0.2} \mathrm{O}_{2}$ powder } \\
\hline 1 & 37 & 0.013 & 0.062 & 62 & $84 \%$ & 0.463 \\
\hline 2 & 38 & 0.013 & 0.062 & 67 & $88 \%$ & 0.543 \\
\hline \multicolumn{7}{|c|}{$\mathrm{CeO}_{2}$ powder } \\
\hline 1 & 55 & 0.019 & 0.087 & 95 & $86 \%$ & 0.886 \\
\hline 2 & 54 & 0.019 & 0.087 & 98 & $91 \%$ & 0.980 \\
\hline \multicolumn{7}{|c|}{ CeMS (ceria microspheres) } \\
\hline 1 & 49 & 0.017 & 0.081 & 96 & $98 \%$ & 1.117 \\
\hline 2 & 50 & 0.017 & 0.087 & 99 & $99 \%$ & 1.167 \\
\hline
\end{tabular}

The thermochemical redox activity of the microstructured ceria spheres was further investigated in packed-bed solar reactors during several consecutive thermochemical $\mathrm{H}_{2} \mathrm{O}$ and $\mathrm{CO}_{2}$ splitting cycles, performed with various operating conditions under real concentrated solar irradiation.

Cycling experiments were first performed in a solar-heated tubular reactor at the focus of a solar concentrator. This solar reactor (Supplementary Material §2) has been described in detail elsewhere ${ }^{28,29,37}$. Table 2 a summarizes the thermochemical cycle conditions and the calculated $\mathrm{O}_{2}$ and $\mathrm{H}_{2}$ yields obtained by integrating the production rate versus time profiles (over six cycles). During the first cycle (Fig. 2a), the microspheres were cycled between $1400^{\circ} \mathrm{C}$ (reduction) and below $1050^{\circ} \mathrm{C}$ (oxidation), and produced about $135 \mu \mathrm{mol} / \mathrm{g} \mathrm{H}_{2}$ (about twice the amount of produced $\left.\mathrm{O}_{2}\right)$. Reduction was performed in pure $\mathrm{Ar}(0.25 \mathrm{NL} / \mathrm{min})$ and oxidation with water injection $\left(0.228 \mathrm{~g} / \mathrm{min}+0.25 \mathrm{NL} / \mathrm{min} \mathrm{Ar}, \mathrm{H}_{2} \mathrm{O}\right.$ mole fraction: $\left.53 \%\right) . \mathrm{O}_{2}$ evolved during material heating from about $840^{\circ} \mathrm{C}$ (first traces detected) and was more significantly released from $1000^{\circ} \mathrm{C}$. Then, it continually increased until reaching a maximum when the maximum temperature was reached and the dwell maintained $\left(1400^{\circ} \mathrm{C}\right)$. The steam injection during cooling below $1050^{\circ} \mathrm{C}$ (without any solar input) led to a sharp $\mathrm{H}_{2}$ concentration increase. The peak production rate was reached shortly $(\sim 1 \mathrm{~min})$ after injection, 
and then $\mathrm{H}_{2}$ concentration decreased steadily until becoming negligible, denoting reaction completion.

During the second cycle the temperature was increased up to only $1360^{\circ} \mathrm{C}$ and then decreased immediately, which resulted in a lower amount of $\mathrm{O}_{2}$ produced, thereby also decreasing the $\mathrm{H}_{2}$ production yield $(68 \mu \mathrm{mol} / \mathrm{g})$. Peak $\mathrm{H}_{2}$ production rates were about $1.4 \mathrm{~mL} / \mathrm{min} / \mathrm{g}$ in both cycles.

In subsequent experiments (Fig. 2b), four consecutive cycles were achieved with a reduction temperature of $1400^{\circ} \mathrm{C}$. The amount of $\mathrm{O}_{2}$ released during each cycle was almost stable (64$67 \mu \mathrm{mol} / \mathrm{g}$ ). Oxidation was performed below $1150^{\circ} \mathrm{C}$ (steam injection during cooling) for the $2^{\text {nd }}$ cycle (whereas below $1050^{\circ} \mathrm{C}$ for the other cycles), which in turn caused a significant decrease of the $\mathrm{H}_{2}$ production rate (peak at $0.67 \mathrm{~mL} / \mathrm{min} / \mathrm{g}$ ) when compared to the other cycles (1.1-1.2 $\mathrm{mL} / \mathrm{min} / \mathrm{g})$. The production yields and rates were stable, suggesting a relatively good stability of the CeMS physico-chemical characteristics during cycles.
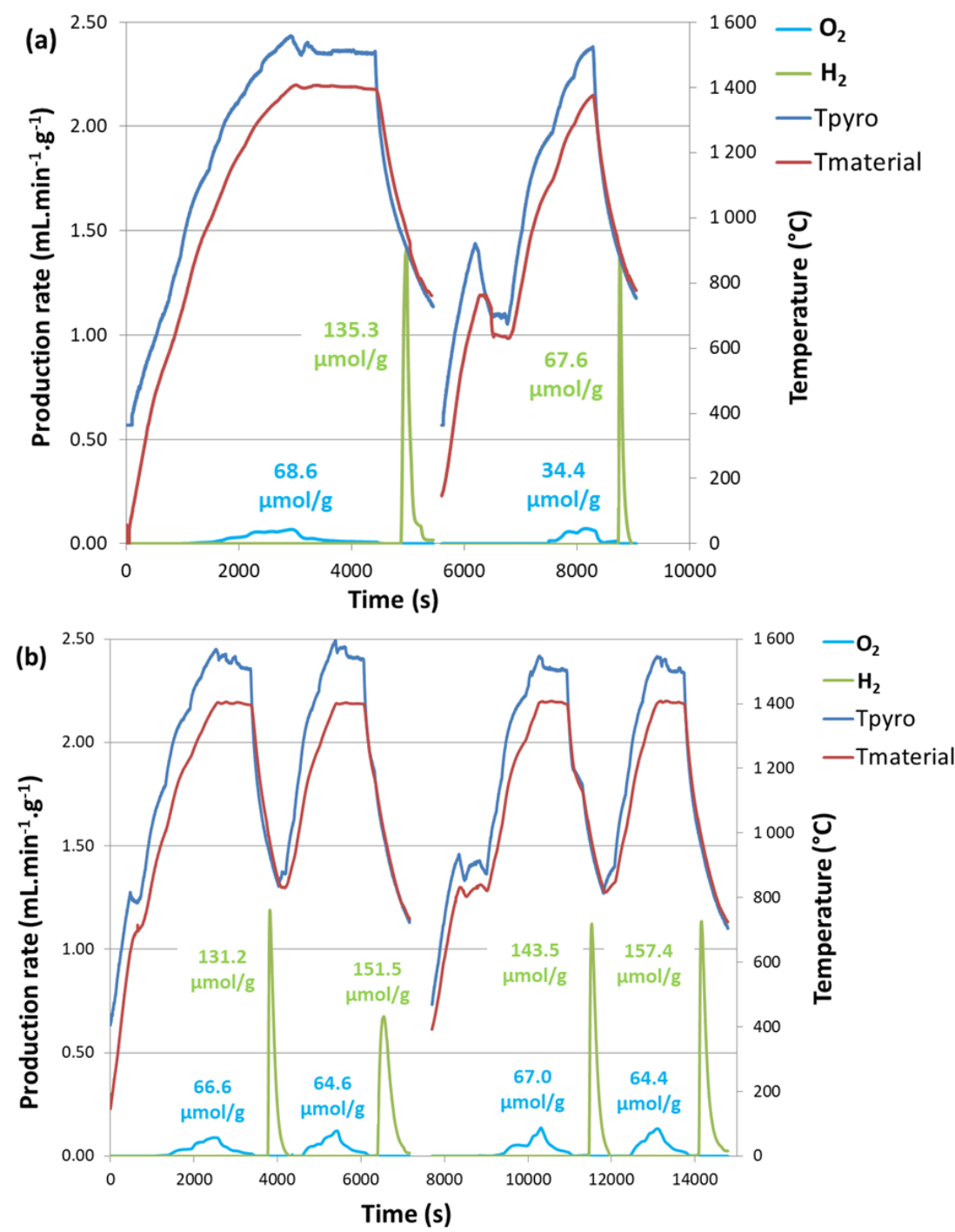
Figure 2: Thermochemical $\mathrm{H}_{2} \mathrm{O}$-splitting cycles with CeMS in the solar tubular packed-bed reactor: (a) effect of the reduction temperature $\left(\mathrm{T}_{\mathrm{ox}}<1050^{\circ} \mathrm{C}\right)$, and $(\mathrm{b})$ effect of the oxidation temperature $\left(\mathrm{T}_{\mathrm{red}}=1400^{\circ} \mathrm{C}\right)$ on $\mathrm{O}_{2}$ and $\mathrm{H}_{2}$ production rates.

The ceria microspheres were then cycled in a directly-heated cavity-type solar reactor, previously used to investigate the reactivity of ceria foams and microstructured materials ${ }^{18,19,30,38}$. The reactor was positioned at the focus of a vertical-axis $2 \mathrm{~m}$-diameter concentrator (Figure 3). Both $\mathrm{H}_{2} \mathrm{O}$ and $\mathrm{CO}_{2}$-splitting cycles were performed using a substantial mass of ceria ( $62 \mathrm{~g})$, with the possibility to operate at low total pressure $(\sim 0.1$ bar) in flowing gas thanks to the use of a vacuum pump at the outlet. An alumina tube (confiner) was placed at the center of the cavity to help maintaining the redox CeMS material as a packed-bed in the annular region between the cavity wall and the tube. A cardboard insulation disk was placed at the bottom of the cavity to minimize CeMS particle escape. The temperature was measured by B-type thermocouples and a pyrometer. Continuous outlet gas analysis was performed to measure the concentrations of $\mathrm{O}_{2}$ (trace oxygen electrochemical analyzer), $\mathrm{H}_{2}$ (thermal conductivity detection), and $\mathrm{CO}_{2}$ and $\mathrm{CO}$ (NDIR sensors), after flowing through a gas drying unit. Two other reactor cavity configurations (Fig. S1-S2) were used to perform cycles \#1, \#2, and \#3.

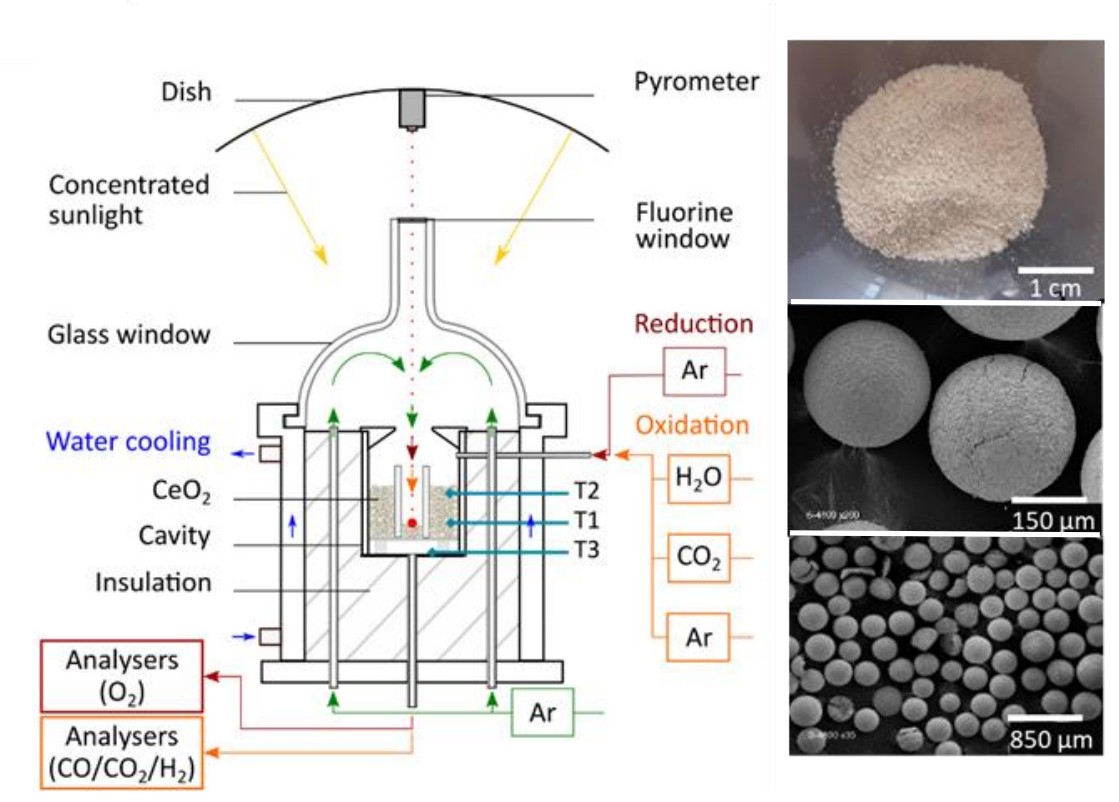

Figure 3: Scheme of the directly-heated solar reactor and images of CeMS (red arrows: gas flow during reduction step; orange arrows: gas flow during oxidation step; green arrows: Ar flow injected during both cycle steps to protect the glass window and sweep the cavity; and blue arrows: water-cooling). 
In order to study the redox activity of CeMS in the directly-irradiated solar reactor, consecutive thermochemical cycles were performed with different operating parameters (Table 2b). Nineteen cycles were performed with CeMS, corresponding to $32 \mathrm{~h}$ of continuous on-sun operation during 5 days (Fig. 4a). Such experiments helped to assess the sensitivity of performance to the process conditions and to demonstrate the CeMS material stability under real cycling conditions.
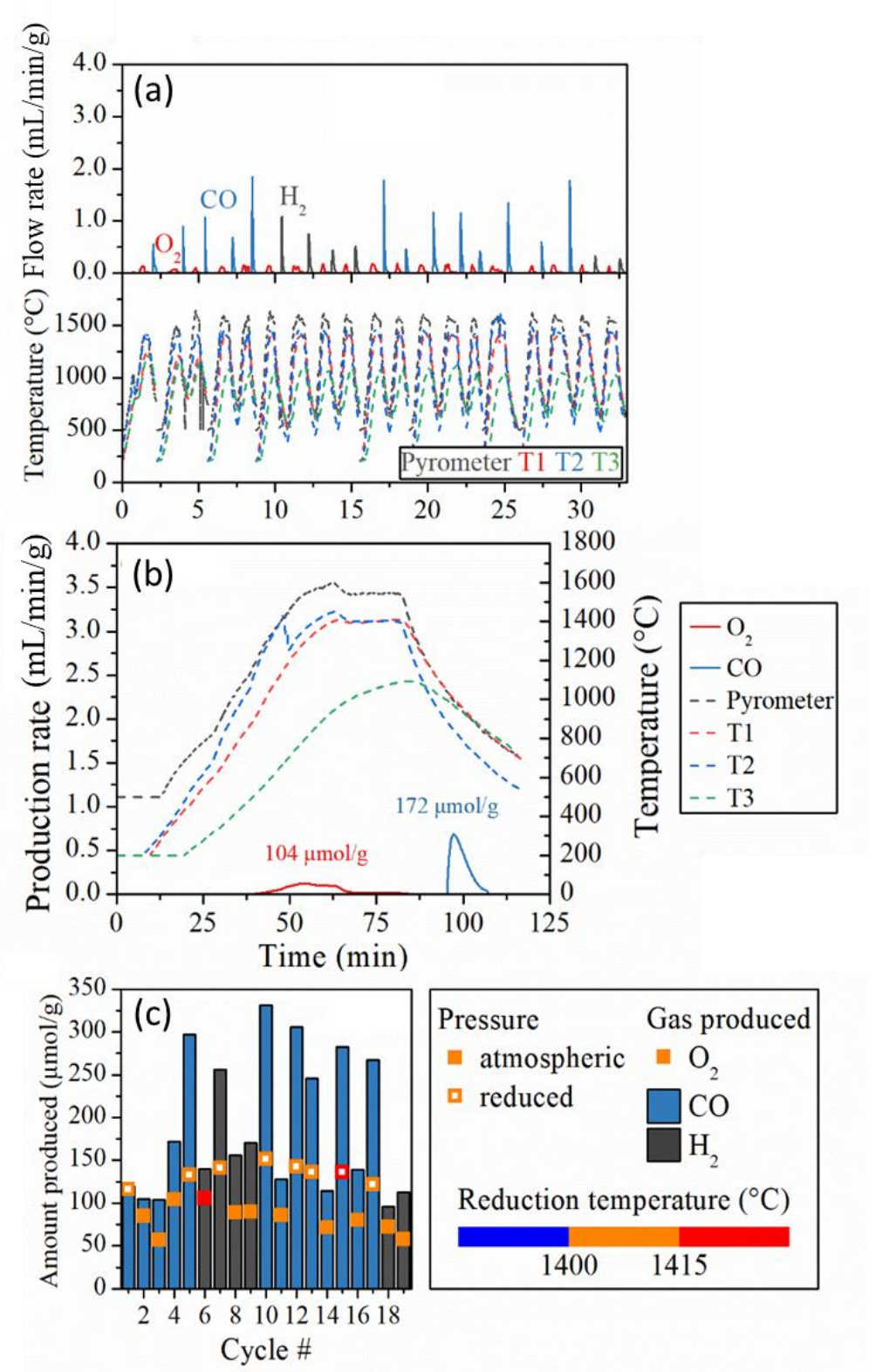

Figure 4: (a) Evolution of $\mathrm{O}_{2}$ and fuel production rates during the performed 19 cycles, along with the temperature profiles for CeMS (T1, T2, T3: temperatures of sample interior, sample surface, and cavity bottom), (b) Example of a cycle at atmospheric pressure (cycle \#4: 


$$
\mathrm{T} 1_{\text {red }}=1400^{\circ} \mathrm{C}, \mathrm{T} 1_{\mathrm{ox}}=1050-850^{\circ} \mathrm{C}, 25 \mathrm{~mol} \% \mathrm{CO}_{2} \text { ), (c) Evolution of gas yields over cycles }
$$

(squares: $\mathrm{O}_{2}$ production, bars: fuel production, reduction temperature indicated by the square color).

Figure $4 \mathrm{~b}$ shows the evolution of $\mathrm{O}_{2}$ and $\mathrm{CO}$ production rates for cycle \#4 (reduction step at $1400^{\circ} \mathrm{C}$ under $\mathrm{Ar}$ at atmospheric pressure, and oxidation step in $25 \mathrm{~mol} \% \mathrm{CO}_{2}$ with a temperature decrease in the range $1050-850^{\circ} \mathrm{C}$ ). For this cycling condition, the peak $\mathrm{CO}$ production rate $(0.7 \mathrm{~mL} / \mathrm{min} / \mathrm{g})$ was lower than the one obtained in TGA (Table 1), presumably because of the lower $\mathrm{CO}_{2}$ mole fraction (25\%). This is confirmed with cycles \#2, $\# 11$, \#14, \#16 performed at the same $\mathrm{CO}_{2}$ mole fraction, yielding a $\mathrm{CO}$ production rate in the range $0.4-0.9 \mathrm{~mL} / \mathrm{min} / \mathrm{g}$. In contrast, the oxidation rate was improved with pure $\mathrm{CO}_{2}$ feed, because reaction kinetics is favored with high $\mathrm{CO}_{2}$ partial pressure. Additionally, an increase of $\mathrm{CO}_{2}$ inlet flow rate favors mass transfer and decreases the $p_{\mathrm{CO}} / p_{\mathrm{CO} 2}$ ratio (equilibrium constant of oxidation reaction), thus shifting the thermodynamic equilibrium toward $\mathrm{CO}$ formation. The fuel production rate also increased when the oxidation temperature was decreased (cycle \#2 vs. cycle \#3), because the oxidation step (exothermal) is thermodynamically favored at low temperatures. Figure $4 \mathrm{c}$ plots the oxygen (squares) and the fuel (bars) production yields related to the reduction temperature. The cycles performed under low pressure during the reduction step (hollow squares) showed both improved reduction extent ( $\delta$ up to 0.052 in cycle \#10) and fuel production yield $(331 \mu \mathrm{mol} / \mathrm{g})$, as previously reported $^{18}$.

All the cycles showed a high re-oxidation yield, and the CO production yield was closely related to the reduction extent, depending on both the reduction temperature and the oxygen partial pressure. Thus, decreasing $p_{\mathrm{O} 2}$ during the reduction step (via total pressure decrease) led to increased reduction extent and associated fuel production yield. As a result, CO yields above $300 \mu \mathrm{mol} / \mathrm{g}$ were achieved (at $\mathrm{P} \sim 0.1$ bar during the reduction). The highest fuel production rate reached $1.8 \mathrm{~mL} / \mathrm{min} / \mathrm{g}$ (cycles \#5 and \#10) when carrying out the reduction step at low total pressure $\left(\sim 0.1\right.$ bar) and the oxidation step under pure $\mathrm{CO}_{2}$. However, operating the redox steps at two different pressures (swing of total pressure) is not convenient for process application and cost. Indeed for each cycle, the total pressure would need to be decreased for the reduction step and then increased for the oxidation, inducing undesirable energy losses. 
Noticeably, the oxidation rate was also affected by the total pressure during the oxidation step. Cycle \#12 was performed with a constant pressure of 0.1 bar during both reduction and oxidation steps (isobaric). This operating mode avoids pressure swing between redox steps, thus saving energy. However, the $\mathrm{CO}$ production rate was decreased to $1.2 \mathrm{~mL} / \mathrm{min} / \mathrm{g}$ (cycle \#12 vs. cycle \#10), while a $\mathrm{CO}$ yield above $300 \mu \mathrm{mol} / \mathrm{g}$ (complete oxidation) was still achieved. The lower total pressure during oxidation translates into a lower $p_{\mathrm{CO} 2}$, thereby decreasing the oxidation rate (same effect as the $\mathrm{CO}_{2}$ mole fraction). Therefore, maintaining a low pressure throughout the whole cycle is beneficial to promote the reduction extent and fuel yield, at the expense of a lower fuel production rate during oxidation.

Several water-splitting cycles were also performed, yielding similar $\mathrm{H}_{2}$ yields than $\mathrm{CO}$, but the oxidation rate with $\mathrm{H}_{2} \mathrm{O}$ was somewhat lowered in comparison with the case of $\mathrm{CO}_{2}$ (because $\mathrm{CO}_{2}$ splitting is thermodynamically more favorable). However, the steam mole fraction was lower, which may also explain the lower oxidation rate with $\mathrm{H}_{2} \mathrm{O}$. The $\mathrm{H}_{2}$ production rates and yields were consistent with those obtained in the tubular solar reactor (Fig. 2).

The production rates measured with CeMS compared favorably with the performance of other ceria material structures. In comparison, a peak $\mathrm{CO}$ production rate of $1.2 \mathrm{~mL} / \mathrm{min} / \mathrm{g}$ was achieved using ceria foams cycled with more favorable operating conditions (reduction step at $1500^{\circ} \mathrm{C}$ under $\left.10 \mathrm{mbar}\right)^{20}$. Moreover, similar fuel production was reached using corktemplated ceria granules under similar conditions ${ }^{28}$. This clearly points out the promise and relevance of the studied microsphere morphology integrated within solar reactors.

The instant solar-to-fuel conversion efficiency (determined from the calorific value of the produced fuel to the solar power input ${ }^{18}$ ) was $0.60 \%$ in cycle \#4 and increased to $1.75 \%$ in cycles \#5 and \#10 performed at low reduction pressure (enhanced fuel production rates). These efficiencies could be further enhanced by increasing the amount of loaded ceria via reactor scaling up ${ }^{39}$.

For the total mass of ceria loaded in the reactor (62.24 g), and the number of cycles performed (19) during the corresponding continuous on-sun operation (32h), the CeMS material produced 2.67 $\mathrm{L} \mathrm{O}_{2}, 1.29 \mathrm{~L} \mathrm{H}_{2}$, and 3.54 L CO.

Regarding the thermochemical stability, a moderate performance decline was noticed: for example the CO yield dropped from $172 \mu \mathrm{mol} / \mathrm{g}$ to $114 \mu \mathrm{mol} / \mathrm{g}$ between cycles \#4 and \#14 for similar operating conditions. This may result from either material sintering and/or a loss of 
reactive material in the solar cavity (such issues were not encountered in the indirectly-heated tubular solar reactor).

As the microspheres are small $(<350 \mu \mathrm{m})$ and spherical, their flowability is high and the particles tend to pass through the insulation interstices at the cavity bottom (and thus cannot reach sufficiently high temperature to be reduced). Indeed, significant amounts of particles were found in interstices when the reactive material was removed from the reactor, providing credit to this hypothesis. Moreover, after cycle \#14, a layer ( 5 mm thick) of agglomerated particles was observed at the directly-heated surface (upper part of the cavity). Thus, the CeMS material was removed and the agglomerates were crushed for being separated and reintroduced in the cavity (with a new total mass of $59.54 \mathrm{~g}$ ). An additional top-layer ( $2 \mathrm{~mm}$ thick) of alumina particles was added to avoid direct CeMS exposure to high-flux thermal radiation (overheating). After cycle \#14, no variation of the production rates was observed, revealing that the redox activity of the microspheres was not significantly altered.

The material cubic fluorite structure remained stable during cycling (Fig. S3). Noticeably, few CeMS particles reacted with the alumina tube in the upper part of the cavity (directly irradiated by concentrated sunlight), leading to the formation of $\mathrm{CeAlO}_{3}$ (Fig. S3c). However, due to the very small fraction of the reacted/modified material, no performance decline attributed to this reaction could be detected.

The microstructural characterization of the reactive particles after thermochemical cycles confirmed a slight sintering of grains within the microspheres. The SEM observations of CeMS before and after thermochemical cycles in the directly-heated solar reactor are compared in Figure 5 (and Fig. S4-5). The spherical morphology of the particles was maintained for the cycled samples. The ceria grain sizes within the microspheres were in the range 0.5-2 $\mu \mathrm{m}$ before cycling. After cycling, the few particles that reacted with alumina parts of the cavity showed a strong increase of their grain sizes up to 13-30 $\mu \mathrm{m}$ (Fig. S6), while the others (majority) only showed a slight increase of their grain sizes up to 6-9 $\mu \mathrm{m}$. Such a limited grain growth and the associated sintering phenomena could hardly explain alone the progressive decrease of production yield (especially $\mathrm{O}_{2}$ ) observed with CeMS over cycles. More consistently, this decline of performance was ascribed to the loss of CeMS material flowing out at the bottom of the cavity. 


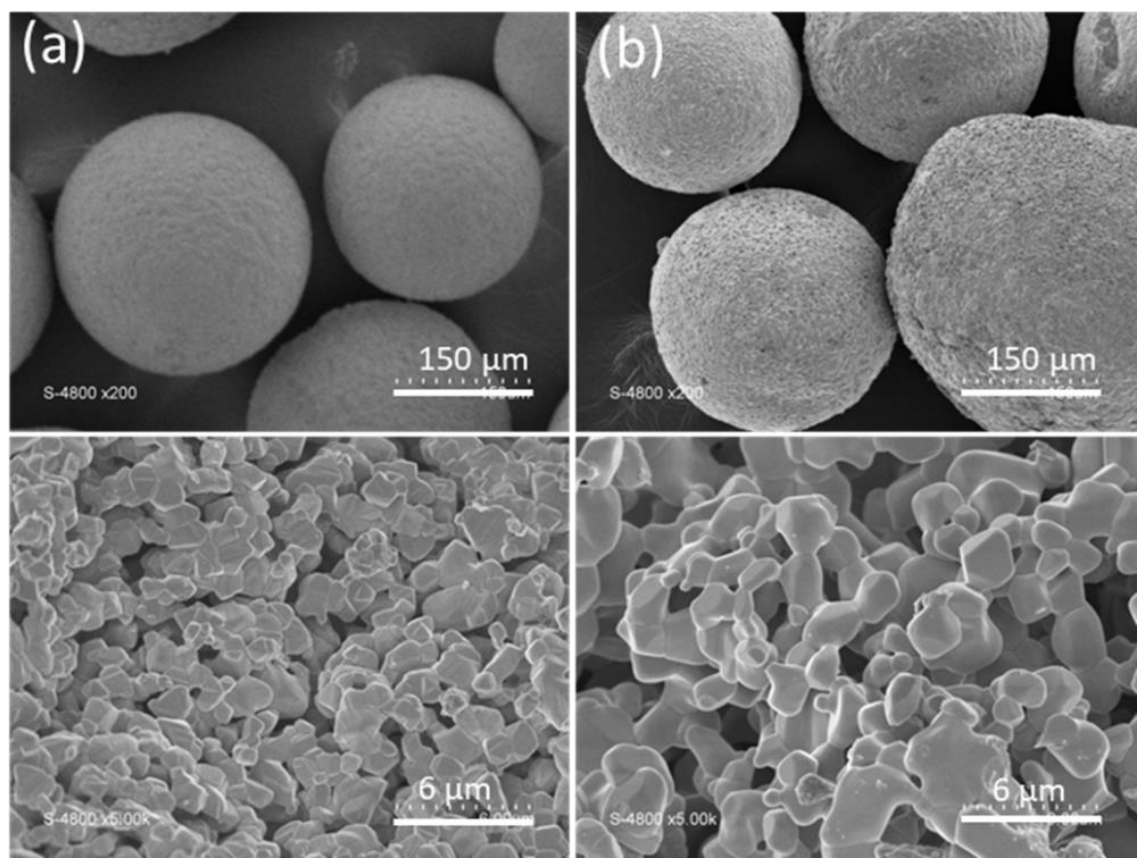

Figure 5: SEM images of CeMS prior (a) and after (b) thermochemical cycling in the solar reactor (19 cycles).

In conclusion, based on the superior redox performance in comparison with ceria powders and reticulated foams, the innovative porous ceria spherical morphology was proven efficient for $\mathrm{H}_{2}$ and $\mathrm{CO}$ fuel production from solar-driven two-step redox cycles. The thermochemical performance of the new material was assessed in both indirectly and directly-heated packedbed solar reactors. Indirect heating was more suitable to alleviate sintering issues usually caused by direct irradiation of the reactive material. In contrast, direct radiative heating was more efficient in terms of solar energy utilization because inherent heat losses due to intermediate heating via heat transfer wall can be avoided. Additionally, a higher amount of reactive material was cycled with the directly-irradiated solar reactor for a similar solar power input (thus improving the solar-to-fuel conversion efficiency). In future applications, such ceria microspheres could be integrated in particle-based solar reactors with different possible operating modes: (i) single reactor (packed-bed, fluidized-bed, moving bed...) with alternating reaction steps, or (ii) dual reactors for separate reduction and oxidation steps with a transfer of ceria particles between both reactors (favored by their good flowability) ${ }^{40}$. Such particle-based reactors could hardly be considered with powders (cohesive) that easily form aggregates. The microsphere morphology is also an attractive alternative to less scalable porous monoliths (RPCs). The spherical particles can thus be used in conventional reactor technologies, while enabling both high packing density and large accessible internal porosity for redox reactions. The microspheres are also adapted for continuous operation (with bed 
circulation) and have thus high potential for improving solar process robustness and scalability. 
Table 2: Operating parameters along with oxygen and fuel production amounts for CeMS (oxidation performed during free cooling with oxidizing gas injection starting at the mentioned temperature). The gas production yields were determined by time integration of the gas production rates (method described in Supplementary Material §3). (*) indicates an overpressure during oxidation reaction ( 0.930 bar instead of 0.865 bar) due to the reactor configuration, $(* *)$ indicates an oxidation step performed at reduced pressure.

\begin{tabular}{|c|c|c|c|c|c|c|c|c|c|}
\hline \multirow[b]{2}{*}{$\begin{array}{c}\text { Cycle } \\
\#\end{array}$} & \multicolumn{4}{|c|}{ Reduction step } & \multicolumn{5}{|c|}{ Oxidation step } \\
\hline & $\begin{array}{c}\text { T1 } \\
\text { reduction } \\
\text { step } \\
\\
\left({ }^{\circ} \mathrm{C}\right) \\
\end{array}$ & $\begin{array}{c}\text { Pressure } \\
\text { (bar) }\end{array}$ & $\begin{array}{l}\text { Ar flow } \\
\text { rate during } \\
\text { reduction } \\
\text { (L/min) }\end{array}$ & $\begin{array}{c}\mathbf{O}_{2} \text { produced } \\
(\mu \mathrm{mol} / \mathrm{g})\end{array}$ & $\begin{array}{c}\text { T1 } \\
\text { oxidation } \\
\text { step } \\
\\
\left({ }^{\circ} \mathrm{C}\right) \\
\end{array}$ & $\begin{array}{l}\text { Oxidant } \\
\text { gas } \\
\text { (oxidant } \\
\text { molar } \\
\text { fraction) }\end{array}$ & $\begin{array}{c}\text { Oxidant } \\
\text { flow } \\
\text { rate } \\
\text { (Ar flow } \\
\text { rate) } \\
\text { (L/min) }\end{array}$ & $\begin{array}{c}\text { Fuel } \\
\text { produced }\end{array}$ & $\begin{array}{c}\text { Peak fuel } \\
\text { production } \\
\text { rate }\end{array}$ \\
\hline \multicolumn{10}{|c|}{ (a) Indirectly-heated tubular solar reactor } \\
\hline 1 & 1400 & 0.875 & 0.25 & 68.6 & $<1050$ & $\mathrm{H}_{2} \mathrm{O}(0.53)$ & $\begin{array}{c}0.28 \\
(0.25)\end{array}$ & 135.3 & 1.40 \\
\hline 2 & 1360 & 0.875 & 0.25 & 34.4 & $<1050$ & $\mathrm{H}_{2} \mathrm{O}(0.53)$ & $\begin{array}{c}0.28 \\
(0.25)\end{array}$ & 67.6 & 1.41 \\
\hline 3 & 1400 & 0.875 & 0.25 & 66.6 & $<1050$ & $\mathrm{H}_{2} \mathrm{O}(0.53)$ & $\begin{array}{c}0.28 \\
(0.25)\end{array}$ & 131.2 & 1.19 \\
\hline 4 & 1400 & 0.875 & 0.25 & 64.6 & $<1150$ & $\mathrm{H}_{2} \mathrm{O}(0.53)$ & $\begin{array}{c}0.28 \\
(0.25)\end{array}$ & 151.5 & 0.67 \\
\hline 5 & 1410 & 0.875 & 0.25 & 67.0 & $<1050$ & $\mathrm{H}_{2} \mathrm{O}(0.53)$ & $\begin{array}{c}0.28 \\
(0.25) \\
\end{array}$ & 143.5 & 1.12 \\
\hline 6 & 1400 & 0.875 & 0.25 & 64.4 & $<1050$ & $\mathrm{H}_{2} \mathrm{O}(0.53)$ & $\begin{array}{c}0.28 \\
(0.25)\end{array}$ & 157.4 & 1.14 \\
\hline \multicolumn{10}{|c|}{ (b) Directly-heated solar reactor } \\
\hline $1 *$ & 1409 & 0.414 & 1.2 & 116.0 & $<1077$ & $\mathrm{CO}_{2}(0.25)$ & $\begin{array}{c}0.40 \\
(1.20) \\
\end{array}$ & 120.0 & 0.55 \\
\hline 2 & 1410 & 0.868 & 1.2 & 84.7 & $<1051$ & $\mathrm{CO}_{2}(0.23)$ & $\begin{array}{c}0.30 \\
(1.00)\end{array}$ & 105.0 & 0.90 \\
\hline 3 & 1410 & 0.870 & 1.2 & 56.4 & $<960$ & $\mathrm{CO}_{2}(0.23)$ & $\begin{array}{c}0.30 \\
(1.00)\end{array}$ & 103.6 & 1.06 \\
\hline 4 & 1409 & 0.871 & 1.2 & 104.0 & $<1050$ & $\mathrm{CO}_{2}(0.25)$ & $\begin{array}{c}0.40 \\
(1.20) \\
\end{array}$ & 172.0 & 0.68 \\
\hline 5 & 1412 & 0.104 & 1.2 & 132.8 & $<1052$ & $\mathrm{CO}_{2}(1.00)$ & $\begin{array}{c}2.00 \\
(0.00)\end{array}$ & 297.2 & 1.85 \\
\hline 6 & 1418 & 0.875 & 1.2 & 105.8 & $<764$ & $\mathrm{H}_{2} \mathrm{O}(0.17)$ & $\begin{array}{c}0.25 \\
(1.20)\end{array}$ & 140.0 & 1.09 \\
\hline 7 & 1411 & 0.123 & 1.2 & 140.9 & $<1045$ & $\mathrm{H}_{2} \mathrm{O}(0.17)$ & $\begin{array}{c}0.25 \\
(1.20) \\
\end{array}$ & 256.0 & 0.74 \\
\hline 8 & 1415 & 0.918 & 1.2 & 88.6 & $<1040$ & $\mathrm{H}_{2} \mathrm{O}(0.17)$ & $\begin{array}{c}0.25 \\
(1.20)\end{array}$ & 156.0 & 0.44 \\
\hline 9 & 1412 & 0.915 & 1.2 & 89.6 & $<1051$ & $\mathrm{H}_{2} \mathrm{O}(0.37)$ & $\begin{array}{c}0.54 \\
(0.90)\end{array}$ & 170.0 & 0.51 \\
\hline 10 & 1409 & 0.107 & 1.2 & 151.1 & $<1053$ & $\mathrm{CO}_{2}(1.00)$ & $\begin{array}{c}2.00 \\
(0.00)\end{array}$ & 331.0 & 1.78 \\
\hline 11 & 1410 & 0.875 & 1.2 & 85.2 & $<1064$ & $\mathrm{CO}_{2}(0.25)$ & $\begin{array}{c}0.40 \\
(1.20)\end{array}$ & 128.0 & 0.46 \\
\hline
\end{tabular}




\begin{tabular}{cccccccccc}
\hline $12^{* *}$ & 1407 & 0.102 & 1.2 & 142.0 & $<1053$ & $\mathrm{CO}_{2}(1.00)$ & $\begin{array}{c}2.00 \\
(0.00)\end{array}$ & 306 & 1.2 \\
\hline 13 & 1408 & 0.099 & 1.2 & 135.8 & $<1046$ & $\mathrm{CO}_{2}(0.67)$ & $\begin{array}{c}2.00 \\
(1.00)\end{array}$ & 246.0 & 1.15 \\
\hline 14 & 1408 & 0.873 & 1.2 & 71.2 & $<1066$ & $\mathrm{CO}_{2}(0.25)$ & $\begin{array}{c}0.40 \\
(1.20)\end{array}$ & 114.1 & 0.41 \\
\hline 15 & 1419 & 0.083 & 1.2 & 136.0 & $<1051$ & $\mathrm{CO}_{2}(1.00)$ & $\begin{array}{c}2.00 \\
(0.00)\end{array}$ & 282.3 & 1.30 \\
\hline 16 & 1412 & 0.871 & 1.2 & 79.6 & $<953$ & $\mathrm{CO}_{2}(0.25)$ & $\begin{array}{c}0.40 \\
(1.20)\end{array}$ & 139.3 & 0.60 \\
\hline 17 & 1408 & 0.089 & 1.2 & 121.7 & $<950$ & $\mathrm{CO}_{2}(1.00)$ & $\begin{array}{c}2.00 \\
(0.00)\end{array}$ & 267.0 & 1.70 \\
\hline 18 & 1410 & 0.870 & 1.2 & 71.5 & $<912$ & $\mathrm{H}_{2} \mathrm{O}(0.17)$ & $\begin{array}{c}0.25 \\
(1.20)\end{array}$ & 96.1 & 0.33 \\
\hline 19 & 1411 & 0.912 & 1.2 & 57.4 & $<1061$ & $\mathrm{H}_{2} \mathrm{O}(0.17)$ & $\begin{array}{c}0.25 \\
(1.20)\end{array}$ & 112.6 & 0.27 \\
\hline
\end{tabular}

\section{Supplementary Material}

See Supplementary material for description of the materials characterization techniques, packed-bed tubular solar reactor and other tested cavity-type conical bed solar reactor configurations, determination of gas production rates and yields in solar reactors, and additional structural and morphological characterizations.

\section{Acknowledgments}

The directly-irradiated solar reactor used in this work was funded by the French National Agency for Research (ANR, SUNFUEL project, contract $N^{\circ}$ ANR-16-CE06-0010). The authors thank Prof. A. Ayral (IEM) for supplying the CeMS sample and its associated physicochemical characteristics, Dr. J. Jouannaux and D. Cot (IEM) for SEM observations, and R. Garcia (PROMES) for solar reactor design.

\section{Data Availability}

The data that supports the findings of this study are available within the article and its supplementary material.

\section{References}

${ }^{1}$ Y. Mao, Y. Gao, W. Dong, H. Wu, Z. Song, X. Zhao, J. Sun, and W. Wang, Applied Energy 267, 114860 (2020).

${ }^{2}$ Abanades, ChemEngineering 3, 63 (2019). 
${ }^{3}$ Y. Lu, L. Zhu, C. Agrafiotis, J. Vieten, M. Roeb, and C. Sattler, Progress in Energy and Combustion Science 75, 100785 (2019).

${ }^{4}$ S. Abanades, A. Haeussler, and A. Julbe, Chemical Engineering Journal 422, 130026 (2021).

${ }^{5}$ R.C. Pullar, R.M. Novais, A.P.F. Caetano, M.A. Barreiros, S. Abanades, and F.A.C. Oliveira, Frontiers in Chemistry 7, 34 (2019).

${ }^{6}$ A. Haeussler, S. Abanades, J. Jouannaux, M. Drobek, A. Ayral, and A. Julbe, AIMS Materials Science 6, 657 (2019).

${ }^{7}$ W.C. Chueh and S.M. Haile, Phil. Trans. R. Soc. A. 368, 3269 (2010).

${ }^{8}$ H. Kaneko, H. Ishihara, S. Taku, Y. Naganuma, N. Hasegawa, and Y. Tamaura, Journal of Materials Science 43, 3153 (2008).

${ }^{9}$ H. Kaneko, T. Miura, H. Ishihara, S. Taku, T. Yokoyama, H. Nakajima, and Y. Tamaura, Energy 32, 656 (2007).

${ }^{10}$ A. Le Gal, S. Abanades, N. Bion, T. Le Mercier, and V. Harlé, Energy Fuels 27, 6068 (2013).

${ }^{11}$ Q.-L. Meng, C. Lee, T. Ishihara, H. Kaneko, and Y. Tamaura, International Journal of Hydrogen Energy 36, 13435 (2011).

12 J.R. Scheffe and A. Steinfeld, Energy Fuels 26, 1928 (2012).

${ }^{13}$ S. Li, V.M. Wheeler, P.B. Kreider, R. Bader, and W. Lipiński, Energy Fuels 32, 10848 (2018).

${ }^{14}$ D. Arifin and A.W. Weimer, Solar Energy 160, 178 (2018).

${ }^{15}$ P. Charvin, S. Abanades, E. Beche, F. Lemont, and G. Flamant, Solid State Ionics 180, 1003 (2009).

${ }^{16}$ P. Furler, J. Scheffe, M. Gorbar, L. Moes, U. Vogt, and A. Steinfeld, Energy Fuels 26, 7051 (2012).

${ }^{17}$ P. Furler, J. Scheffe, D. Marxer, M. Gorbar, A. Bonk, U. Vogt, and A. Steinfeld, Phys. Chem. Chem. Phys. 16, 10503 (2014).

${ }^{18}$ A. Haeussler, S. Abanades, A. Julbe, J. Jouannaux, M. Drobek, A. Ayral, and B. Cartoixa, Chemical Engineering Research and Design 156, 311 (2020).

${ }^{19}$ A. Haeussler, S. Abanades, A. Julbe, J. Jouannaux, and B. Cartoixa, Energy 201, 117649 (2020).

${ }^{20}$ D. Marxer, P. Furler, M. Takacs, and A. Steinfeld, Energy Environ. Sci. 10, 1142 (2017).

${ }^{21}$ P. Furler, J.R. Scheffe, and A. Steinfeld, Energy Environ. Sci. 5, 6098 (2012).

${ }^{22}$ A.C. Gladen and J.H. Davidson, Solar Energy 139, 524 (2016). 
${ }^{23}$ W.T. Gibbons, L.J. Venstrom, R.M. De Smith, J.H. Davidson, and G.S. Jackson, Phys. Chem. Chem. Phys. 16, 14271 (2014).

${ }^{24}$ N.D. Petkovich, S.G. Rudisill, L.J. Venstrom, D.B. Boman, J.H. Davidson, and A. Stein, J. Phys. Chem. C 115, 21022 (2011).

${ }^{25}$ L.J. Venstrom, N. Petkovich, S. Rudisill, A. Stein, and J.H. Davidson, Journal of Solar Energy Engineering 134, (2011).

${ }^{26}$ S.G. Rudisill, L.J. Venstrom, N.D. Petkovich, T. Quan, N. Hein, D.B. Boman, J.H. Davidson, and A. Stein, J. Phys. Chem. C 117, 1692 (2013).

${ }^{27}$ C.D. Malonzo, R.M. De Smith, S.G. Rudisill, N.D. Petkovich, J.H. Davidson, and A. Stein, J. Phys. Chem. C 118, 26172 (2014).

${ }^{28}$ F.A.C. Oliveira, M.A. Barreiros, S. Abanades, A.P.F. Caetano, R.M. Novais, and R.C. Pullar, Journal of CO2 Utilization 26, 552 (2018).

${ }^{29}$ F.A.C. Oliveira, M.A. Barreiros, A. Haeussler, A.P.F. Caetano, A.I. Mouquinho, P.M. Oliveira e Silva, R.M. Novais, R.C. Pullar, and S. Abanades, Sustainable Energy \& Fuels 4, 3077 (2020).

${ }^{30}$ A. Haeussler, S. Abanades, F.A. Costa Oliveira, M.A. Barreiros, A.P.F. Caetano, R.M. Novais, and R.C. Pullar, Energy Fuels 34, 9037 (2020).

${ }^{31}$ T. Delahaye, M. Caisso, and S. Picart, European Patent EP15200498.2 (22 June 2016).

${ }^{32}$ M. Caisso, F. Lebreton, D. Horlait, S. Picart, P.M. Martin, R. Bès, C. Renard, P. Roussel, D.R. Neuville, K. Dardenne, J. Rothe, T. Delahaye, and A. Ayral, Journal of Solid State Chemistry 218, 155 (2014).

${ }^{33}$ A. Le Gal, S. Abanades, and G. Flamant, Energy Fuels 25, 4836 (2011).

${ }^{34}$ F. Call, M. Roeb, M. Schmücker, C. Sattler, and R. Pitz-Paal, J. Phys. Chem. C 119, 6929 (2015).

${ }^{35}$ S. Abanades, A. Legal, A. Cordier, G. Peraudeau, G. Flamant, and A. Julbe, J. Mater. Sci. 45, 4163 (2010).

${ }^{36}$ A. Le Gal and S. Abanades, J. Phys. Chem. C 116, 13516 (2012).

${ }^{37}$ M.M. Nair and S. Abanades, Energy Fuels 30, 6050 (2016).

38 A. Haeussler, S. Abanades, A. Julbe, J. Jouannaux, and B. Cartoixa, Journal of CO2 Utilization 41, 101257 (2020).

${ }^{39}$ N.P. Siegel, J.E. Miller, I. Ermanoski, R.B. Diver, and E.B. Stechel, Ind. Eng. Chem. Res. 52, 3276 (2013).

${ }^{40}$ I. Ermanoski, N.P. Siegel, and E.B. Stechel, Journal of Solar Energy Engineering 135, (2013). 
